\title{
The value of formal planning for strategic decisions: review of empirical research
}

\author{
J. Scott Armstrong \\ University of Pennsylvania, armstrong@wharton.upenn.edu
}

Follow this and additional works at: https://repository.upenn.edu/marketing_papers

Part of the Management Sciences and Quantitative Methods Commons

\section{Recommended Citation}

Armstrong, J. S. (1982). The value of formal planning for strategic decisions: review of empirical research. Retrieved from https://repository.upenn.edu/marketing_papers/22

Postprint version. Published in Strategic Management Journal, Volume 3, Number 3, July-September 1982, pages 197-211. The author has asserted his/her right to include this material in ScholarlyCommons@Penn.

Publisher URL: http://www3.interscience.wiley.com/cgi-bin/jhome/2144

This paper is posted at ScholarlyCommons. https://repository.upenn.edu/marketing_papers/22

For more information, please contact repository@pobox.upenn.edu. 


\title{
The value of formal planning for strategic decisions: review of empirical research
}

\author{
Abstract \\ A review of research from organizational behavior supported the guidelines by corporate planners: that is, \\ use an explicit approach for setting objectives, generating strategies, evaluating strategies, monitoring \\ results, and obtaining commitment. To determine whether these findings could be applied to strategic \\ decision making in organizations, a review was made of all published field research on the evaluation of \\ formal planning. Formal planning was superior in 10 of the 15 comparisons drawn from 12 studies, while \\ informal planning was superior in only two comparisons. Although this research did not provide sufficient \\ information on the use of various aspects of the planning process, mild support was provided for having \\ participation by stakeholders. Formal planning tended to be more useful where large changes were \\ involved, but, beyond that, little information was available to suggest when formal planning is most \\ valuable. Future research should assess the formal planning process, the situation in which it is used, and \\ its effects on the total system. \\ Disciplines \\ Management Sciences and Quantitative Methods

\section{Comments} \\ Postprint version. Published in Strategic Management Journal, Volume 3, Number 3, July-September \\ 1982, pages 197-211. The author has asserted his/her right to include this material in \\ ScholarlyCommons@Penn. \\ Publisher URL: http://www3.interscience.wiley.com/cgi-bin/jhome/2144
}




\title{
The Value of Formal Planning for Strategic Decisions: Review of Empirical Research
}

\author{
J. Scott Armstrong \\ Strategic Management Journal, 3 (1982), 197-211 \\ Reprinted with permission from John Wiley \& Sons, Ltd.
}

\begin{abstract}
A review of research from organizational behavior supported the guidelines by corporate planners: that is, use an explicit approach for setting objectives, generating strategies, evaluating strategies, monitoring results, and obtaining commitment. To determine whether these findings could be applied to strategic decision making in organizations, a review was made of all published field research on the evaluation of formal planning. Formal planning was superior in 10 of the 15 comparisons drawn from 12 studies, while informal planning was superior in only two comparisons. Although this research did not provide sufficient information on the use of various aspects of the planning process, mild support was provided for having participation by stakeholders. Formal planning tended to be more useful where large changes were involved, but, beyond that, little information was available to suggest when formal planning is most valuable. Future research should assess the formal planning process, the situation in which it is used, and its effects on the total system.
\end{abstract}

Formal planning seems valuable-for strategic decision making because so much money is spent on it. Some of the companies that use formal planning believe that it improves profits and growth. In AI-Bazzaz and Grinyer (1980), 48 per cent of the companies reported such a benefit. But some companies do not agree. Furthermore, researchers have obtained conflicting findings; some claim planning is useful, while others claim the opposite.

This paper provides a systematic examination of published empirical evidence to answer three questions:

- Is formal planning useful for strategic decision making?

- Which aspects of the planning process are most useful?

- In what situations is planning most useful?

First, this paper proposes a framework for the evaluation of planning; this section draws upon research from organizational behavior. Next, it reviews field research on the value of formal strategic planning in organizations. Finally, it presents suggestions for further research.

\section{A Framework For Evaluation}

The basic framework for evaluation is a simple one, used in many scientific evaluations:

(a) What is the treatment?

(b) Under what conditions was the treatment used?

(c) What were the results?

This section first examines these three questions in the context of planning, then discusses each in more detail. 
The treatment refers to the "planning process". A definition is needed to distinguish formal from informal planning. This definition should be detailed enough so that the planning process could be replicated by others.

The conditions refer to the 'situation' in which planning is used. External (environmental) and internal (organizational) factors should be described in detail.

The "results" refer to the effects of the planning process on the total system. This includes the intended as well as the unintended outcomes. It includes financial as well as non-financial results, and long-term as well as short-term results. It includes everyone affected by the organization.

\section{The Formal Planning Process}

Much research exists on the usefulness of various aspects of formal planning. This research, from organizational behavior, is relatively recent; much of it has appeared since 1970. It is used here to provide a description of an effective planning process. In general, this research has supported the advice provided in publications describing how to conduct the corporate planning process (e.g., Ansoff, 1965; Stainer, 1969).

Formal strategic planning calls for an explicit process for determining the firm's long-range objectives, procedures for generating and evaluating alternative strategies, and a system for monitoring the results of the plan when implemented. During each of these steps, it is important that a systematic procedure be used to gain commitment of those who will be affected by the plan. These steps are summarized in Figure 1 and are discussed below. (A more extensive description of each of these steps is provided in Armstrong, 1982).

\section{Figure 1. Formal strategic planning process}

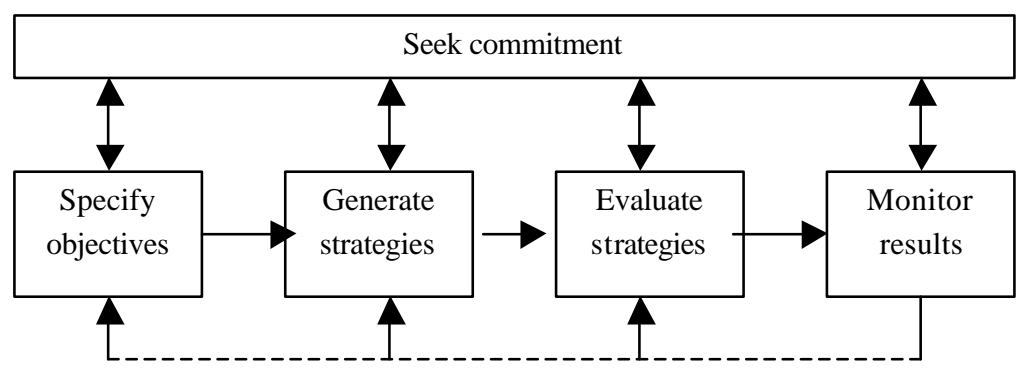

\section{Specify Objectives}

The specification of objectives (goals) has long been regarded as a major aspect of formal planning. The objectives should be written clearly. They should start with the ultimate objectives for the organization, then should be translated into specific measurable objectives. In addition, the objectives should be challenging.

Substantial evidence exists on the value of setting objectives. Reviews of this research are provided by Latham and Yukl (1975). Tolchinsky and King (1980), and Locke et al. (1981). Most of the research consists of laboratory studies. Some studies, however, have taken place in firms. For example, Kim and Hamner (1976) found that explicit objectives improved performance for service jobs at Bell Telephone; Ivancevich (1977) found that specific objectives for skilled technicians in an equipment and parts manufacturing company proved to be superior to instructions to "do your best;" and, in the only experimental industrial study, Latham and Kinne (1974) found that explicit objectives improved productivity and reduced absenteeism in 20 pulpwood logging operations.

In addition to improvements in performance, explicit objectives have led to greater satisfaction among participants in organizations (Arvey et al., 1976; Ivancevich, 1977; Katerberg, 1980). 
Strategic planning calls for an examination of the complete system. Consequently, many objectives are involved. "Stakeholder" analysis can help to ensure that all of the important objectives are included. This analysis calls first for a listing of all groups that contribute to the organization. For most firms, this would include creditors, stockholders, employees, consumers, suppliers, dealers, and the local community. The planners should then identify explicit objectives for each group (e.g., return on investment for stockholders; stability, good wages, and good working conditions for employees; reliable and safe products for consumers; adequate return on investment for retailers; and low pollution for the local community).

\section{Generate Strategies}

Formal planning calls for the generation of alternative strategies. These strategies should be written in enough detail to allow for an explicit evaluation (the next step). Evidence from studies in organizational behavior suggests that the generation of the strategies should be completed before any evaluation begins (see, e.g. Maier, 1963).

Two guidelines are typically recommended for the development of strategies. First, an attempt should be made to provide comprehensive strategies; that is, the plan should consider all important factors. Numerous books and articles have provided checklists and flow charts to help ensure that comprehensive plans can be developed (e.g., Ansoff, 1965). The second guideline is that the plan contain slack resources; that is, extra time, money, and facilities should be held in reserve. This recognizes uncertainty and adds flexibility to the plan.

Alternative strategies can improve the adaptability of the organization in two ways. First, by explicitly examining alternatives, it is likely that the organization will find alternatives that are superior to the current procedure. Second, the organization may encounter environmental changes; if alternative (contingency) plans have been prepared for these changes, the organization can react in a systematic way.

The generation of alternative strategies has been widely recommended as good practice in planning. The literature describes complex techniques for generating strategies. For example, numerous sophisticated techniques have been proposed as aids in the selection of marketing strategies. Although organizations seem satisfied with these procedures (Coe, 1981), 1 have been unable to find empirical evaluations of their usefulness. Many basic questions remain unanswered. How many strategies should be generated for a given environment? When is it practical to prepare contingency plans to deal with alternative environments? Should the strategies be generated by those who will eventually be responsible for the implementation of a strategy?

Research has, however, identified better procedures for generating strategies. For example, synectics and brainstorming are clearly superior to the traditional (unstructured) group meeting for improving both the quantity and quality of ideas (Bouchard, 1972).

\section{Evaluate Alternative Strategies}

Formal planning calls for a systematic procedure for evaluating the various alternatives. First the alternatives must be screened to ensure that they do not violate any constraints. The feasible strategies should then be rated against each of the listed objectives. Various procedures can be used here, such as checklists, the Delphi technique (with internal experts), or the "devil's advocate" (where one person is given the role to challenge a proposed strategy). Traditional meetings, as commonly used in informal planning, are seldom adequate.

Unfortunately, little research is available. One exception is the research on the "devil's advocate." Cosier (1978) presented subjects with two plans for a simulated environment; subjects using the devil's advocate procedure were more likely to select the most appropriate plan in this simulation. 


\section{Monitor Results}

The plan should provide for explicit feedback at given intervals. To allow for corrective action, the following should be monitored:

(1) changes in the environment,

(2) changes in the organization's capabilities and in the capabilities of its competitors (strengths and weaknesses),

(3) actions taken by the organization,

(4) actions taken by competitors, and

(5) results.

The monitoring of results should relate to the objectives for each stakeholder. This comparison between results and objectives can provide a basis for action. The monitoring system should have explicit performance standards so that the firm can determine whether the strategies are achieving the desired results.

The value of feedback has been well established in laboratory studies (see reviews by Tolchinsky and King, 1980; Locke, Cartledge and Koeppel, 1968) and in organizational studies (see review by Ilgen, Fisher and Taylor, 1979, and the study by Wexley and Nemeroff, 1975). Some studies found that feedback is useful only if it relates to goals (e.g., Erez, 1977, in a laboratory study, and Becker, 1978, in a field study to reduce residential energy usage). Others found that feedback had an independent effect, perhaps because some goals are intrinsically obvious (e.g., Nemeroff and Cosentino, 1979, and Seligman and Darley, 1977). Certainly., however, feedback is more useful if it relates to prespecified goals (Kim and Hamner, 1976; Locke et al., 1981).

The monitoring system is expected to. have a greater impact if it is tied into the organization's incentive system. This helps the organization maintain commitment to the goals represented by the strategic plan. This does not always occur; organizations sometimes focus solely on the stockholders or on the personal goals of the managers. Also; they seem to stress short-range goals at the expense of the long-range goals.

Apparently, not many firms have a systematic procedure for monitoring the success of their strategic plans. Horovitz (1979), in a survey of the planning practices of 52 large firms in Great Britain, France and West Germany, found that virtually none had an explicit procedure for monitoring results of their long-range plans. Typically, they relied on short-range budget controls.

\section{Seek Commitment}

It is not sufficient to develop plans. Plans are frequently ignored. Other times they are used to rationalize a course of action previously decided. Formal planning calls for an explicit procedure for gaining commitment to the plan. This implies, for example, a need for meetings; Al-Bazzaz and Grinyer (1980) found that the perceived contribution of planning was higher when the firms had more meetings. Presumably, the need for meetings carries through all phases of planning.

Commitment to objectives is expected to be higher if the various stakeholders participate in the objective setting process. In other words, "self-set" goals are expected to be superior to goals set by others. This generalization is based on laboratory studies (e.g., Bass, 1977; Latham, Mitchell and Dossett, 1978; Latham and Saari, 1979) and on field studies (see Blumberg, 1968, for a review, and see Rosenberg and Rosenstein, 1980). On the other hand, assigned goals were useful in many situations. For example, assigned goals were accepted by new trainees on a job and by workers who were not subject to group norms (see Latham and Yukl's 1976 study of typists, and Ivancevich's 1977 study of skilled technicians). But where no legitimate basis exists for the assignment of goals, they would be 
expected to have little impact. For example, in Dossett, Latham and Saari (1980), the assignment of goals improved the response rate to a mail, survey only when a goal (time deadline) was assigned by the respondent's supervisor.

Participation in the generation and evaluation of alternative strategies is often helpful in gaining commitment for a plan. Perlmutter and Monty (1977) reviewed laboratory experiments showing that if subjects believed they had some control over the situation, they performed more effectively. Van de Ven (1980) described how participation was used successfully by organizations introducing child care programs. Participation seems especially important when the strategies involve large changes.

To maintain commitment to the plan, it is useful to develop a monitoring system that provides relevant and accurate feedback. This feedback should be provided in a timely fashion with fixed reporting periods. It should inform all key stakeholders so they can see how their interests are affected.

Rather than seeking commitment to the plan, managers sometimes use planning to gain control over others. This may help to explain why formal planning is more popular among higher than lower level management. For example, in Ang and Chua (1979), 80 per cent of top management reported that they were "very favorable" towards (formal) long-range planning; only 30 per cent-of the operating managers were "very favorable." This is consistent with the findings in the survey by Al-Bazzaz and Grinyer (1980) that the most important difficulties related to the interface of formal planning with the line departments. Al-Bazzaz and Grinyer (1980) also found that the perceived success of planning was higher in companies where the chief planner was in a lower position in the organization. This suggests planning might be more successful if formal authority is not invoked. In other words, if planning is used to control others, its impact may be detrimental because operating management might feel less responsible for the success of strategic decisions.

\section{Situations Favoring the Use of Formal Strategic Planning}

In what situations would formal strategic planning be expected to be most useful? Little study has been done in this area. Based on a review of the organizational behaviour literature and on my own experience, I propose four characteristics of the situation to be important: inefficient markets, large changes, high uncertainty, and high complexity of the task. My hypotheses are that each of these factors increases the need for formal planning.

In addition to my literature review and experience, I conducted a convenience sample survey of the participants at the Strategic Management Society Conference in London in October 1981. I asked participants at one session to provide a written response to the question:

\section{Under what conditions is formal planning most useful for strategic decision making?}

Of the 24 participants who returned this questionnaire, 21 responded to this question. Of these, only one respondent said that formal planning would be useful in `all situations'. Fourteen respondents cited environmental change as a big factor; interestingly, 11 of these respondents thought that formal planning was less appropriate when change was rapid. Four responses related to complexity, three related to uncertainty, and one to inefficient markets. One respondent suggested that management support was an important condition. No other factors were mentioned. Clearly, little agreement existed in this group on the conditions under which formal planning is most appropriate. My hypotheses are discussed below.

\section{Inefficient Markets}

If an objective is obvious, little need exists for a formal objective setting process. An efficient market makes the objectives more obvious. Little evidence has been found to suggest that an organization can make better decisions than a relatively efficient market. An organization in an efficient market can react to meet the demands of its employee, financial and consumer stakeholders.

As inefficiencies are introduced, formal planning may become more useful. An inefficient market provides little information on the proper pricing strategy. It also raises serious questions on how to allocate rewards among 
the various stakeholders. Formal planning can examine the pricing issue in a systematic way. It can address the allocation of rewards in an explicit and open manner. Thus, planning might be more appropriate for regulated industries and non-profit organizations.

Some people argue just the opposite. Formal planning is most useful for profit-oriented firms because those with poor planning might not survive. The difference in these two viewpoints arises from the fact that the first puts more emphasis on an analysis of the total system. Regulated industries and non-profit organizations can exist indefinitely when they use resources inefficiently. Profit-oriented firms get fewer opportunities to misuse resources because a more efficient organization could take over.

\section{Large Changes}

Changes can occur from the outside (the environment) or from the inside (a change in the organization's resources). Most organizations are designed to deal with small outside changes and they typically resist inside changes. But for large changes, the standard organizational response becomes less relevant. As a result, I hypothesize that formal planning is more important where changes are large.

Some evidence exists that formal planning is more relevant where change is large. Lindsay and Rue (1980) provided survey results in which firms in more complex and faster changing environments said they were more likely to use formal planning, but their study did not examine whether such a procedure led to better performance. Evidence that formal planning is most appropriate when change is large was provided by Thune and House (1970); they found that planning was more helpful -in markets characterized by a high rate of technological innovation and new product introductions.

\section{High Uncertainty}

If it is clear what will happen and when, the need for planning seems small. As uncertainties increase, the organization can benefit by planning to deal with these uncertainties. (Theoretically, with complete uncertainty, planning would be of little value.) My hypothesis is that over the practical range for uncertainty, high uncertainty would require more planning. I found little prior evidence on this issue, and it is not difficult to find arguments against this hypothesis.

\section{High Complexity}

More complex tasks create a higher need for a plan to ensure that the various bits and pieces fit together. Thus, I hypothesize that firms involved with complex production, financial and marketing processes would have a greater need for planning.

I found no empirical evidence on this issue. It would appear to be one of the least controversial of the four hypotheses; however, one of my survey respondents felt that formal planning was most appropriate for simple situations.

\section{Interaction among Hypotheses}

Given the uncertainty about the various hypotheses, it seems reasonable initially to treat each of the hypotheses independently. Planning is hypothesized to be relevant in cases where all four of the preceding conditions hold. When one or more of these conditions does not apply, planning. would be expected to be. less valuable (or perhaps even be detrimental) to the performance of the organization:

An example of an organization where all four of the conditions apply would be a company building atomic reactors in the U.S.A. It has a complex task, large changes are involved, uncertainty is high, and the market is inefficient. At the other extreme would be a typical middle-price restaurant operating in a stable neighbourhood in 
New York City and contemplating no major changes. Formal strategic planning- should be useful for the former but not the latter.

Some strategic decisions will create the above conditions. For example, mergers or new .product introductions can involve large changes. If the new product involves a patented technological breakthrough, it can also lead to an inefficient market (monopoly power) and high complexity. Formal planning is expected to be useful in these situations.

Keep in mind that these hypotheses on the relationship of the situation to planning are not drawn from significant prior research: Furthermore, there may be other, more important, characteristics of the situation that have been overlooked by me and by my convenience sample.

\section{Results of Formal Planning}

One of the expected benefits of formal planning is that it will avoid sub-optimization. It should lead to greater success in light of all of the organization's objectives. Thus, an examination should be made of the impact of planning upon each of the stakeholders. The previous discussion on monitoring provided the necessary conditions for the evaluation of planning from the viewpoint of the complete system.

\section{Field Research on Strategic Planning}

The above research from organizational psychology suggests that formal planning should be useful for strategic decision making. I also proposed hypotheses on when formal planning would be most useful. But these generalizations were drawn mostly from studies of individuals and small groups. Is it possible to generalize to large organizations? To assess this, I analyzed all empirical field research that was relevant to the use of formal planning for strategic decision making by organizations.

The literature on formal planning began in the early 1950s and it is extensive. Hofer's (1976) comprehensive review of research on formal planning produced over 100 references to published and unpublished studies. His review was helpful to my study because it identified those studies that did not attempt an evaluation of formal planning. In fact, few studies have made such an attempt.

A listing of all published empirical studies on the subject is provided in Table 1. All of these studies involved U.S.A. organizations, except for Grinyer and Norburn (1975), who used firms in the U.K., and Harju (1981), whose study was done in Finland. All studies used mail surveys to assess the planning process except for two: Grinyer and Norburn (1975) used questionnaires plus interviews, while Van de Ven (1980) used questionnaires, interviews, observation, and examination of planning reports. All of the studies were non-experimental except for Van de Ven (1980) who used a quasiexperimental design (an experiment with no random assignment of the treatments).

The published studies were examined to determine whether formal planning has been useful and in what situations it has been most useful. To examine this, each of the 15 comparisons in 12 studies was rated to determine:

(a) what aspects of formal planning were actually used,

(b) in what situations formal planning was used, and

(c) what were the results of formal (versus informal) planning?

In addition. to my own ratings for each study, independent assessments were made by Spyros Makridakis and Richard Hoffman. Hoffman and I then discussed each rating. If disagreements remained, the item was coded as "?". Little disagreement arose over the assessment of the "results," some disagreement arose for the "planning process," and much disagreement arose over the `situation'. For the latter, over half the ratings were discussed. 
Copies of the consensus ratings, along with a draft of the paper, were then sent to each of the authors in Table 1. They were asked to comment on the ratings of their study. Replies were received from authors of all of the studies. Most authors agreed with all ratings. In some cases, the authors provided information that was not in their papers. This information and the authors' opinions were used to adjust the final ratings.

Early drafts of my paper were also circulated among researchers from November 1980 to November 1981 to identify any relevant studies that might have been omitted. The studies in Table 1 represent a complete listing of the relevant published research. Unpublished research was excluded due- to cost, the impossibility of ensuring that these papers would be representative of all unpublished studies, and the fact that it would then become impractical for anyone to replicate my study.

The most obvious thing to observe in Table 1 is the number of "??" The studies did not provide sufficient information on the nature of the planning process as 60 per cent of the entries were rated "?". In fact, I was unable, in most studies, to find any description of the planning process. One study, Leontiades and Tezel (1980), treated this lack of definition as an advantage. They asked chief executives to rate the importance of planning, but they did not provide the executives with a definition nor did they ask them for a definition. They claimed (p. 68) that, "An advantage of our approach . . . is that it eliminated the necessity to make an outside judgment on the quality or definition of formal planning." But without a description of the planning techniques; it is not possible to assess the value of planning in a scientific manner.

The lack of information was greater for the "situation," where 70 per cent of the entries were "?". Worse yet, sufficient information was provided in only one-third of the situations that were coded.

The studies had been selected on the condition that they had assessed results. But 80 per cent of the studies limited themselves to an assessment solely of the impact of planning upon the stockholders.

Despite the limitations of the studies in Table 1, a pattern did emerge. In general, formal planning was useful: improved performance was noted in 10 of 15 comparisons, with five of these improvements statistically significant at the 0.05 level. Three comparisons showed no differences. Only two of the comparisons reported negative effects due to formal planning, both from the same study and neither statistically significant (Fulmer and Rue, 1974). This 10 to 2 advantage for formal planning is statistically significant at $\mathrm{p}<0.05$ (ties were excluded). Furthermore, formal planning was not superior in the two situations where it was inappropriate (for the two Fulmer and Rue comparisons at the bottom of Table 1).

Detailed analysis was difficult due to the small sample size and the missing data. As a result, only tentative conclusions are presented below on the importance of various aspects of the planning process and the nature of the situation.

\section{Planning Process}

Objectives were explicitly addressed in all but 2 of the 15 comparisons. Thus, the data do not allow for a comparison of written versus implicit objectives.

In contrast to the attention given to explicit objective setting, only three comparisons were known to use an explicit approach to the generation of strategies. These same studies used an explicit approach to the evaluation of strategies. Formal planning was more successful in each of these three comparisons, significantly so in two. In contrast, formal planning was superior in 7 of the other 12 comparisons. Thus, the tendency favours the hypothesis but the results are not statistically significant.

Exploit monitoring was included in 6 of the 15 comparisons. Surprisingly, planning success tended to be poorer in these studies although the differences were not statistically significant.

Commitment was given explicit attention in four comparisons. In each case, formal planning was superior, significantly so in three cases. This compares with successful planning in 6 of the 11 cases having insufficient information on commitment. Harju's (1981) study examined commitment in detail and concluded that it was an 
important factor. Thus, the evidence favored the hypothesis that it is valuable to have a formal process to gain commitment; however, the results were not statistically significant.

\section{Situational factors}

No conclusions could be drawn with respect to 'uncertainty' or 'complexity' as no explicit measures were provided in any of the studies.

Van de. Ven (1980) and Kallman and Shapiro (1978) were the only studies that clearly involved an inefficient market. Formal planning was superior in these comparisons. However, Herold, House and Thune (1972) seemed to involve an efficient market and planning was successful (though not significantly so).

The area of "change" is the only one allowing for a comparison. Here, planning was successful in all five comparisons with large changes. The superiority was significant in three of these studies. Where the amount of change was small or unknown, planning was helpful in five of the ten comparisons. These results support the hypothesis that planning is most useful where changes are large $(\mathrm{p}<0.10)$.

\section{Limitations}

A major defect running through all of the studies except Van de Ven (1980), Ansoff et al. (1970) and Harju (1981) is that while planning is designed to make the firm more efficient from a total systems viewpoint, the results related primarily to stockholders. Generally, only financial results were examined. These improved financial results were likely to have extended to groups other than the stockholders, but this issue was not specifically addressed in most of the studies.

Planning might improve the results for the total system (i.e., for the various stakeholders in general) even though stockholders do not benefit. For example, in a short-range situation characterized by shortages, it is usually assumed that stockholders will benefit as prices for the firm's product increase. In such a case, formal planning for the total system might be used to provide more benefits for the local community and less for stockholders than might occur under informal planning. Under formal planning, the revenue increases might be used, say, to invest in equipment for pollution control, instead of being paid to stockholders.

\section{Alternative Explanations}

For many of the studies in Table 1, the direction of causality was not clear. Did planning yield higher profits, or did firms with. more profits spend more on planning? Many would argue in favor of the latter hypothesis. If true, this would help to explain the positive outcome in my assessment of planning. This alternative hypothesis is especially serious for five of the last six studies in Table 1 (all except Kallman/Shapiro) because their financial criteria covered the period prior to the time when the distinction was made between those that used formal panning and those that did not. If anything, one would expect benefits to come well after the introduction of planning. If one discards these studies and uses only the first seven comparisons in Table 1, however, the results still favour planning: six improved comparisons with one tie, and three of the six improvements were significant at $\mathrm{P}<0.05$.

Another possible explanation is that the researchers were biased in favour of formal planning and that their methodology was not sufficient to overcome this bias. Terpstra's (1981) evaluation of studies in organizational behavior suggested that this is often a source of bias inasmuch as studies using poorer methods were more likely to yield positive findings.

I rated the studies against Terpstra's (1981) six criteria. These asked whether a study had a:

(1) probability sample,

(2) sample size greater than 30 , 
(3) control group,

(4) random selection for treatment,

(5) pre- and post-test, or

(6) significance level of $\mathrm{p}<0.05$ ?

Each question was rated as a "yes" or "no", and the "yeses" were totalled.

Terpstra (1981) reported perfect agreement between the two coders used in his ratings of research papers. In contrast, I had some difficulty in making the ratings. I tried to be lenient. For example, if the researcher achieved a response rate in a survey of more than 70 per cent, I classified it as a probability sample. (The uncertainty over the ratings was not so great, however, that it would change the conclusions reported below.)

Overall, the studies rated poorly on Terpstra's (1981) scale. They scored an average of 1.5 against an ideal score of 6. This compares poorly, also, with the average of 3.0 for the 52 studies in organizational behavior that were examined by Terpstra (1981). These results suggest that the alternative explanation of bias due to poor methodology is a likely candidate.

As a further test of the potential bias due to poor methodology, I examined the outcomes for the six studies that used the poorest methodology in Table 1 (rated at 0 or 1 on the Terpstra 1981 scale). If this were indeed a source of bias, one would predict that these studies should have had more favorable conclusions about formal planning than did the six studies using better methodology (rated at 2 or 3 ). ${ }^{1}$ The results suggested that poor methodology was not a key factor: only three of the six poorer studies had 'uniformly positive results' (Terpstra's 1981 criterion), while all six of the better studies had positive results. These results were not only opposite to the bias prediction, they were significant at $\mathrm{p}<0.10$ using the Fisher Exact Test.

\section{Suggestions for Further Research}

The literature on formal strategic planning began in a serious way about thirty years ago, although twenty years passed before a scientific study assessed the value of formal strategic planning. Evaluations of this sort began in 1970; however, they generally have overlooked key factors. A continuation of this research at the current pace will require another century before we have sufficient information to assess:

(a) the best way to conduct formal planning,

(b) in what situations formal planning is most useful, and

(c) the impact of formal planning on the whole system.

Progress will occur much more rapidly if the evaluation studies make assessments of the process, the situation, and overall results. Field studies of strategic planning would also benefit substantially from improved research methods. Important here are the uses of probability samples (Harju, 1981, performed best here), control groups (only Van de Ven, 1980, did this), random assignment of the treatment (no studies), and pre-and post-test measurement (done only by Van de Ven, 1980, and Ansoff et al., 1970).

From a practical viewpoint, field research is not a simple matter. It is difficult to use control groups with random assignment of the planning process. Care is needed in the treatment of confidential information. An

\footnotetext{
${ }^{1}$ These "better" studies included Van de Ven (1980), Ansoff et al. (1970), Thune and House (1970), Harju (1981), Karger and Malik (1975), and Wood and LaForge (1979, 1981). A copy of the ratings for each of the studies in Table 1 is available from the author.
} 
alternative approach, laboratory experimentation, allows for control groups and random assignment. It also eliminates the problem of confidentiality. However, it lacks the realism of the field experiment.

Laboratory experiments would be helpful for assessing the various components of the planning process. Thus far, little research has been conducted on the generation of alternative strategies or on their evaluation. Additional research is also needed on techniques for monitoring and commitment.

In addition to the step-by-step examination of planning techniques, laboratory experiments seem relevant for testing the complete planning process. Montanari, Moorhead and Montanari (1980) used such an approach when they trained some subjects in planning, then examined their effectiveness on the "Space Tower Exercise". (In this case, planning did not improve effectiveness. It was not clear whether planning should have worked in this situation, however. Nor was it shown that the experimental groups actually used the planning principles.)

Nutt $(1976,1977)$ also used a laboratory experiment. He evaluated different approaches to planning for health services agencies. Experts were asked to rate decis ions developed by informal planners as well as by two formal approaches to planning. The two approaches were:

(a) a "systems approach", which included setting objectives and an evaluation of alternative strategies, and

(b) a "behavioral approach", which used structured group participation among stakeholders to identify problems, then to solve the problems (but no explicit objective setting or evaluation of alternative strategies).

The systems approach was rated highest in quality of the plans, and the behavioral approach produced more innovative ideas. Informal planning did poorly in both areas. Nutt's $(1976,1977)$ papers did not report on the implementation of the plans.

\section{Conclusions}

Research from organizational behavior has been valuable in studying which aspects of planning are useful. Particularly useful were explicit objective setting and monitoring results. However, further research is needed to identify which aspects of this process are relatively most useful in strategic planning for organizations and which aspects can be ignored.

Research on the application of planning to organizations has been consistent with the position that planning is useful. Comparisons between organizations that use formal planning versus those using informal planning found performance among the formal planners to be superior in ten cases and poorer in only two cases, with three ties. These results were significant $(\mathrm{p}<0.05)$ and they seemed important. Serious research problems were found in these studies, so few conclusions could be drawn about how to plan and when to plan. However, it did seem important to involve key stakeholders in the planning process; and planning seemed most useful in situations involving large changes.

\section{Acknowledgements}

Support for this research was provided by IMEDE, Lausanne, Switzerland. Richard C. Hoffman provided help on various drafts. 


\section{References}

Al-Bazzaz, Shawki and Grinyer, P.H., 1980, "How planning works in practice-A survey of 48 U.K. companies," Long Range Planning 13, August, pp. 30-42.

Ang, James S. and Chua, Jess H., 1979, "Long-range planning in large United States corporations-A survey," Long Range Planning 12, pp. 99-102.

Ansoff, H. Igor, et al. "Does planning pay? The effect of planning on success of acquisitions in American firms," Long Range Planning 3, December 1970, pp.2-7.

Ansoff, H. Igor. Corporate Strategy. McGraw-Hill, New York, 1965.

Armstrong, J. Scott. "Strategic planning and forecasting," in Kenneth Albert (ed.), The Strategic Management Handbook, McGraw-Hill, N.Y. (1982), pp. 2-1 to 2-32.

Arvey, R. D., H. D. Dewhirst and J. C. Boling. `Relationships between goal clarity, participation in goal setting, and personality characteristics on job satisfaction in a scientific organization', Journal of Applied Psychology, 61, 1976, pp. 103-105.

Bass, Bernard M. "Utility of managerial self-planning on a simulated production task with replications in twelve countries," Journal of Applied Psychology, 62, 1977, pp. 506-509.

Becker, L. J. "Joint effect of feedback and goal setting on performance: a field study of residential energy conservation," Journal of Applied Psychology, 63, 1978, pp. 428-433.

Blumberg, Paul. Industrial Democracy: The Sociology of Participation. Schocken Books, New York, 1968.

Bouchard, Thomas J., Jr. “A comparison of two group brainstorming procedures," Journal of Applied Psychology, 56, 1972, pp.418-421.

Coe, Barbara J. "Use of strategic planning concepts by industrial marketers," in Kenneth Bernhardt et al. (eds). The Changing Marketing Environment: New Theories and Applications, American Marketing Association, Chicago, 1981, pp.13-16.

Cosier, Richard A. "The effects of three potential aids for making strategic decisions on prediction accuracy," Organizational Behavior and Human Performance, 22, 1978, pp. 295-306.

Dosset, Dennis L., Gary P. Latham and Lise M. Saari. "The impact of goal setting on survey returns," Academy of Management Journal, 23, 1980, pp. 561-567.

Erez, Miriam. "Feedback: a necessary condition for the goal setting-performance relationship," Journal of Applied Psychology, 62, 1977, pp. 624-627.

Fulmer, Robert M. and Leslie W. Rue. "The practice and profitability of long-range planning," Managerial Planning, 22, May/June 1974, pp. 1-7.

Grinyer, P. H. and D. Norburn. "Planning for existing markets: perceptions of executives and financial performance," Journal of the Royal Statistical Society (A), 138, 1975, pp. 70-97.

Harju, Paavo. Attitude of Strategic Managers Toward Formalized Corporate Planning. School of Economics, Turku, Finland, 1981.

Herold, David, M. R. J. House and S. S. Thune, "Long-range planning and organizational performance: A cross-validation study," Academy of Management Journal, 15, 1972, pp. 91-102. 
Hofer, Charles W. "Research on strategic planning: a survey of past studies and suggestions for future efforts," Journal of Economics and Business, 28, Spring/Summer 1976, pp. 261-286.

Horovitz, J. H. “Strategic control: A new task for top management,” Long-Range Planning, 12, June 1979, pp. 2-7.

Ilgen, Daniel R., C. D. Fisher and M. S. Taylor. "Consequences of individual feedback on behavior in organizations," Journal of Applied Psychology, 64, 1979, pp. 349-371.

Ivancevich, John M. "Different goal setting treatments and their effects on performance and job satisfaction," Academy of Management Journal, 20, 1977, pp. 406-419.

Kallmann, Ernest J. and H. Jack Shapiro. “The motor freight industry-a case against planning," Long Range Planning, 11, 1978, pp.81-86.

Karger, Delmar W. and Zafar A. Malik. "Long-range planning and organizational performance,” Long Range Planning, 8, December 1975, pp.60-64.

Katerberg, Ralph. "An examination of the quality of goal setting: Relationships to job attitudes and role stress," Proceedings of the American Institute for Decision Sciences, November 1980, pp. 387-389.

Kim, Jay S. and W. C. Hamner. "Effect of performance feedback and goal setting on productivity and satisfaction in an organizational setting," Journal of Applied Psychology, 61, 1976, pp.48-57.

Kudla, Ronald J. "The effects of strategic planning on common stock returns," Academy of Management Journal, 23, 1980, 5-20.

Kudla, Ronald J.. "Strategic planning and risk,” Review of Business and Economic Research, 17, Fall 1981,pp.1-14.

Latham, Gary P. and Sydney B. Kinne, III. "Improving job performance through training in goal setting," Journal of Applied Psychology, 59, 1974, pp. 187-191.

Latham, Gary P., Terence R. Mitchell and Dennis L. Dossett, "Importance of participative goal setting and anticipated rewards on goal difficulty and job performance," Journal of Applied Psychology, 63, 1978, pp.163-171.

Latham, Gary P. and Lise M. Saari. "Importance of supportive relationships in goal setting," Journal of Applied Psychology, 64, 1979, pp. 151-156.

Latham, Gary P. and G. A. Yukl. "The effects of assigned and participative goal setting on performance and satisfaction," Journal of Applied Psychology, 61, 1976, pp. 166-171.

Latham, Gary P. and G. A. Yukl. "A review of research on the application of goal setting in organizations," Academy of Management Journal, 18, 1975, pp. 824-845.

Leontiades, Milton and Ahmet Tezel. "Planning perceptions and planning results," Strategic Management Journal, 1, 1980, pp. 65-75.

Lindsay, William M. and Leslie W. Rue. "Impact of the organization environment on the long-range planning process: a contingency view," Academy of Management Journal, 23, 1980, pp. 385-404.

Locke, E. A., N. Cartledge and J. Koeppel. "Motivational effects of knowledge of results: A goal setting phenomenon," Psychological Bulletin, 70, 1968, pp. 474-485.

Locke, Edwin A., K. N. Shaw, L. M. Saari and G. P. Latham. "Goal setting and task performance: 1969-1980," Psychological Bulletin, 90, 1981, pp. 125-152. 
Maier, Norman R. F. Problem-solving Discussions and Conferences. McGraw-Hill, New York, 1963.

Malik, Zafar A. and Delmar W. Karger. "Does long-range planning improve company performance?” Management Review, 64, September 1975, pp.27-31.

Montanari, John R., G. Moorhead and E. O. Montanari. “A laboratory study of a strategic decision making methodology," Proceedings of the American Institute for Decision Sciences, November 1980, pp. $472-474$.

Nemeroff, Wayne F. and Joseph Cosentino. "Utilizing feedback and goal setting to increase performance appraisal interviewer skills of managers," Academy of Management Journal, 22, 1979, pp. 566-576.

Nutt, Paul C. "Field experiments which compared the effectiveness of design methods," Decision Sciences, 7, 1976, pp. 739-758.

Nutt, Paul C. "An experimental comparison of the effectiveness of three planning methods," Management Science, 23, 1977, pp. 499-511.

Perlmutter, Lawrence C. and Richard A. Monty. "The importance of perceived control: fact or fantasy?" American Scientist, 65, 1977, pp. 759-765.

Rosenberg, Richard D. and Eliezer Rosenstein. "Participation and productivity: an empirical study," Industrial and Labor Relations Review, 33, 1980, pp. 355-367.

Rue, Leslie W. and Robert M. Fulmer. "Is long-range planning profitable?" Proceedings of the Academy of Management, Boston, Mass., 1973, pp. 66-73.

Seligman, Clive and J. M. Darley. "Feedback as a means of decreasing residential energy consumption," Journal of Applied Psychology, 62, 1977, pp. 363-368.

Steiner, George A. Top Management Planning. Collier-Macmillan, London, 1969.

Terpstra, David E. "Relationship between methodological rigor and reported outcomes in organization development evaluation research," Journal of Applied Psychology, 66, 1981, pp. 541-543.

Thune, Stanley S. and Robert J. House. "Where long-range planning pays off,” Business Horizons, 13, August 1970, pp. 81-87.

Tolchinsky, Paul D. and Donald C. King. "Do goals mediate the effects of incentives on performance?" Academy of Management Review, 5, 1980, pp.455-467.

Van de Ven, Andrew H. "Problem solving, planning, and innovation, Part. 1. Test of the program planning model," Human Relations, 33, 1980, pp.711-740.

Wexley, Kenneth N. and Wayne F. Nemeroff. "Effectiveness of positive reinforcement and goal setting as methods of management development," Journal of Applied Psychology, 60, 1975, pp.446-450.

Wood, D. Robley, 1r. and R. L. LaForge. "The impact of comprehensive planning on financial performance," Academy of Management Journal, 22, 1979, pp. 516-526.

Wood, D. Robley, Jr. and R. L. LaForge. "Toward the development of a planning scale: an example from the banking industry,” Strategic Management Journal, 2, 1981, pp.209-216. 


\section{[Time span]}

Van de Ven (1980) [1973-1975] Ansoff et al. (1970) [1947-1966]

Thune and House (1970) [1958-1965]

Herold et al. (1972) [1962--1969]

Kudla $(1980,1981)^{5}$ [1960-1975]

Harju (1981, pp. 112-113) [1976-1979]

Karger and Malik (1975)

Malik and Karger (1975) [1964-1973]

Wood and LaForge $(1979,1981)$ [1972-1976]

Kallman and Shapiro (1978)

[1965-1974]6

G rinyer and Norburn (1975)

[1966-1970]

Leontiades and Tezel (1980)

[1971-1977]

Fulmer and Rue (1974)

Rue and Fulmer (1973)

[early 1970s]
9 planners versus 5 non-planners in introduction of

community child care programmes.

Acquisitions by 22 planners versus 40 non

planners.

A: D rug, chemical and machinery industries. 9 planners versus 9 non-planners.

B: Food, oil and steel industries.

8 planners versus 10 non-planners.

D rug and chemical industries: 5 planners and 5 matched

non-planners. (Extension of Thune and House, 1970).

78 planners versus 51 non-planners from

Fortune 500

12 planners with commitment versus 31 lacking either

formal planning or commitment or both.

19 planners versus 19 non-planners among chemical,

drug, electronics and machinery industries.

Survey of banks, interview plus questionnaire.

27 planners versus 9 non-planners.

298 firms in motor freight industry.

Five levels of planning examined.

In-depth interviews with 91 executives from

21 companies in the U.K.

61.cotnpanies from Fortune 1000 largest. industrial

firms.

A: Durable goods: 33 planners versus

20 non-planners.

B: Non-durable goods: 108 planners versus

43 non-planners.

C: Service industries: 27 planners versus 40 non-planners.

$\begin{array}{lllllllllll}\mathrm{F} & \mathrm{F} & \mathrm{F} & \mathrm{F} & \mathrm{F} & \mathrm{Y} & \mathrm{Y} & ? & ? & \mathrm{~F} & \mathrm{~F} \\ \mathrm{~F} & \mathrm{~F} & \mathrm{~F} & ? & ? & ? & \mathrm{Y}) & ? & ? & \mathrm{~F} * & \mathrm{~F} \\ \mathrm{~F} & ? & ? & ? & ? & ? & (\mathrm{Y}) & ? & ? & \mathrm{~F} & ? \\ \mathrm{~F} & ? & ? & ? & ? & ? & (\mathrm{~N}) & ? & ? & 0 & ? \\ \mathrm{~F} & ? & ? & ? & ? & (\mathrm{~N}) & \mathrm{Y} & ? & ? & \mathrm{~F} & ? \\ \mathrm{~F} & ? & ? & \mathrm{~F} & ? & ? & ? & (\mathrm{~N}) & ? & \mathrm{~F} & ? \\ \text { ? } & ? & ? & ? & \mathrm{~F} & ? & ? & ? & ? & \mathrm{~F} * & \mathrm{~F} \\ (\mathrm{~F}) & (\mathrm{F}) & (\mathrm{F}) & (1) & \mathrm{F} & ? & (\mathrm{Y}) & ? & ? & \mathrm{~F} * & ? \\ & & & & & & & & & & \\ (\mathrm{~F}) & ? & ? & ? & \mathrm{~F} & (\mathrm{Y}) & ? & (\mathrm{~N}) & (\mathrm{N}) & \mathrm{F} * & ? \\ \mathrm{~F} & ? & ? & ? & ? & \mathrm{Y} & \mathrm{N} & \mathrm{N} & (\mathrm{N}) & \mathrm{F} & ? \\ \mathrm{~F} & ? & ? & \mathrm{~F} & ? & ? & ? & ? & ? & 0 & ? \\ \text { ? } & ? & ? & ? & ? & ? & ? & ? & ? & 0 & ? \\ \mathrm{~F} & ? & ? & \mathrm{~F} & ? & ? & ? & ? & ? & \mathrm{~F} & ? \\ \mathrm{~F} & ? & ? & \mathrm{~F} & ? & ? & ? & ? & ? & \mathrm{I} & ? \\ \mathrm{~F} & ? & ? & \mathrm{~F} & ? & ? & (\mathrm{~N}) & ? & (\mathrm{~N}) & \mathrm{I} & ?\end{array}$

1 "F" means formal process was used, "I" means informal, and "?" means insufficient information. The parentheses indicate our assumptions in cases that seemed obvious.

2 "Y" is yes, "N" is no. (See note 1 for "?" and parentheses).

3 "F" means that formal planning was superior, "I" means informal, " 0 " means a tie, and "?" means insufficient information. The asterisk means that the results were significant at $p<0.05$.

${ }^{4}$ The time span refers to the years for which the results were examined.

${ }^{5}$ Kudla (1981) reported a reduction in financial risk due to formal planning, thus this study was coded "+" despite the lack of effects in Kudla (1980).

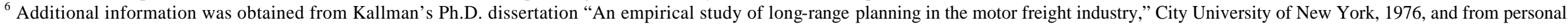
communication with Kallman.

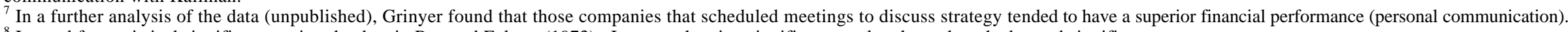
${ }^{8}$ I tested for statistical significance using the data in Rue and Fulmer (1973). In cases showing significant results, the authors had tested significance. 